METHODS \& DESIGNS

\title{
Bigram and trigram frequencies and versatilities in the English language
}

\author{
ROBERT L. SOLSO and PAUL F. BARBUTO, JR. \\ University of Idaho, Moscow, Idaho 83843 \\ and \\ CONNIE L. JUEL \\ University of Texas, Austin, Texas 78712
}

\begin{abstract}
A comprehensive count of bigram and trigram frequencies and versatilities was tabulated for words recorded by Kucera and Francis. Totals of 577 different bigrams and 6,140 different trigrams were found. Their frequencies of occurrence and the number of different words in which they appeared are reported in this article.
\end{abstract}

In recent years the orthographic components involved in letter and word identification have received considerable attention. An important component in some studies has been the positional frequency of letters in the English language (e.g., Mason, 1975); other studies have found that versatility (the number of different words in which letters or letter combinations occur) has affected word processing (e.g., Solso, Topper, \& Macey, 1973).

The current research in letter/word processing has required more comprehensive and contemporary measures of the statistical properties of the English language. In the past, several researchers have counted single-letter frequencies (Lysing, 1936; Underwood \& Schulz, 1960), bigrams (Underwood \& Schulz, 1960; Mayzner \& Tresseit, 1965; Topper, Macey, \& Solso, 1973), and trigrams (Underwood \& Schulz, 1960). These counts, however, have been based on a relatively small sample size and done by hand. Recently, Solso and King (1976) tabulated single-letter frequencies and versatilities based on the Kucera and Francis (1967) norms, which contain about one million words in the English language. The positional frequencies and versatilities have also been recently tabulated for fourand five-letter words (Solso \& King, 1976) and for six-, seven-, and eight-letter words (Solso, 1979) based on the KuXera and Francis norms.

In the present paper a comprehensive count of bigram and trigram frequencies and versatilities is reported. It is anticipated that these data will be of interest to those investigators interested in visual information processing, reading skills, memory search, verbal learning, cognitive models, and related areas.

Paul F. Barbuto, Jr., is currently at Texas Instruments, Dallas, Texas 75260.

\section{METHOD}

All bigram and trigram frequency and versatility counts were based on the Kucera and Francis (1967) tabulation of about one million words in the English language. The Kucera and Francis words are stored on magnetic tape, and the bigram and trigram counts reported in this paper were processed by means of an IBM 370/145 computer. Approximately 40,000 different words with about a total frequency of one million occurrences were used. In the present analysis, all hyphenated words, words containing apostrophes, and numbers were excluded.

The procedure for counting total bigrams and trigrams was as follows: The word "root" has a frequency of $30 /$ million. The frequency of the bigrams RO, OO, and OT were all increased by 30 . In counting, trigrams ROO and OOT were also increased by 30 . For the versatility count, the above bigrams and trigrams were increased by one. The word "cocoon" has a frequency of $3 /$ million. In this case the frequency of bigram $\mathrm{CO}$ was increased by six, as it appears twice in the word, but the versatility count was increased by only one. The other bigram and trigram frequencies were incremented by three and versatilities by one. The word "ringing" has a frequency of $10 /$ million. In this case the frequency of the bigrams IN and NG and the trigram ING were incremented by 20 , and the versatilities incremented by 1 . The other bigram and trigram frequencies were incremented by 10 and versatilities by 1 . A total of 577 bigrams (out of a possible 676) were found in the sample. The total bigram frequency as determined by summing all bigram frequencies was $3,616,085$. The total bigram versatility as determined by summing all bigram versatility was 270,337 . However, because these data represent repeated bigram counts in words, a more practical use of the data may be to use the frequency and versatility counts in relation to the total words and total different words in the Kucera and Francis (1967) count. Thus the bigram EX appeared 6,847 times in about one million words and appeared in 556 different words out of about 40,000 words.

A total of 6,140 trigrams (out of a possible 17,574) were found in the sample. The total trigram frequency as determined by summing all trigram frequencies was $2,662,964$. The total trigram versatilities was 233,420 . As with bigram in terpretation, it may be more useful to use the base of a total of one million words and 40,000 different words. Thus, the trigram HRO appeared 1,490 times in about one million words and appeared in 91 different words out of 40,000 words.

The results of total frequency and versatility counts for bigrams and trigrams are shown in Tables 1 and 2 . 
Table 1

Bigram Frequency and Versatility

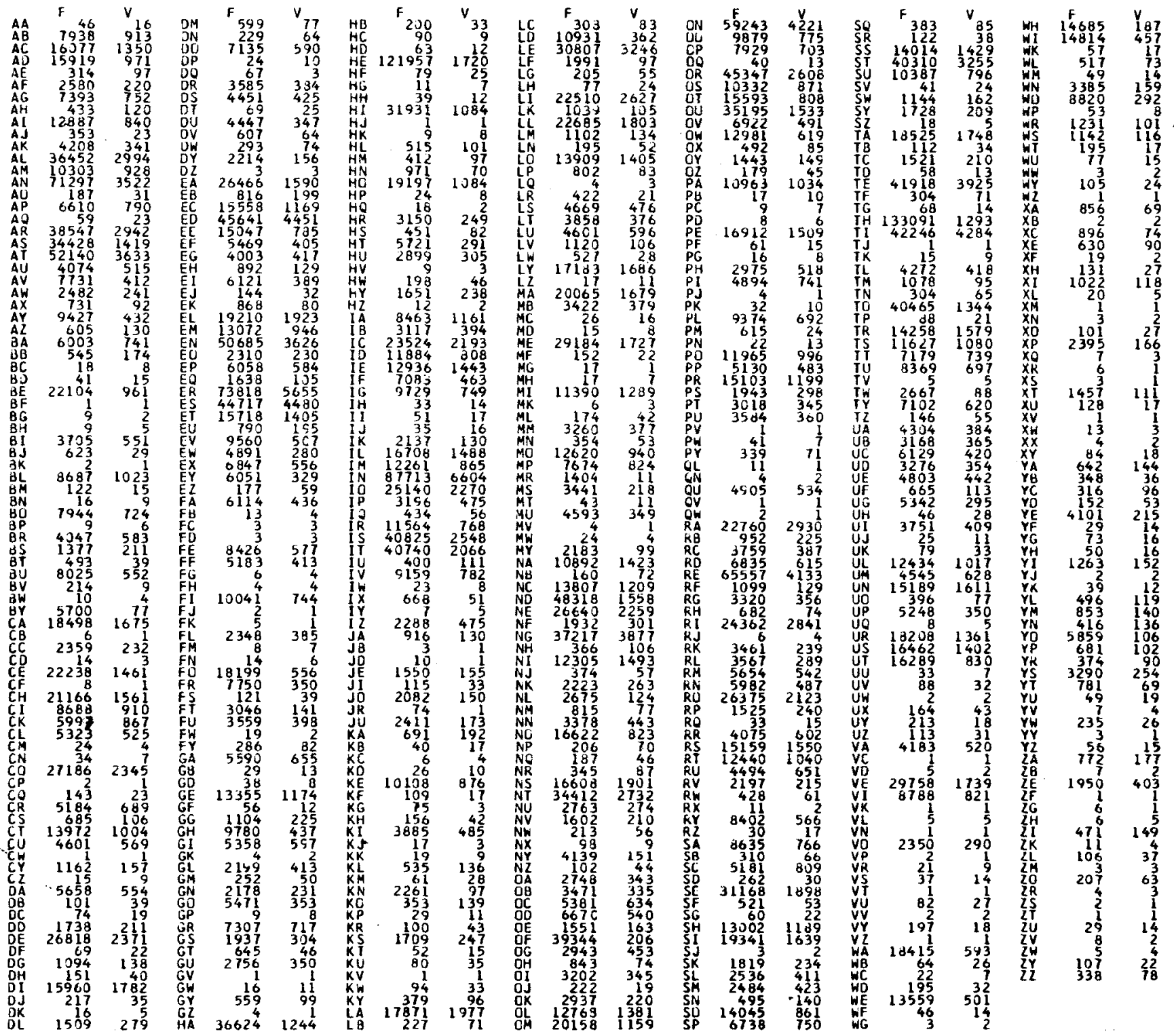

Table 2

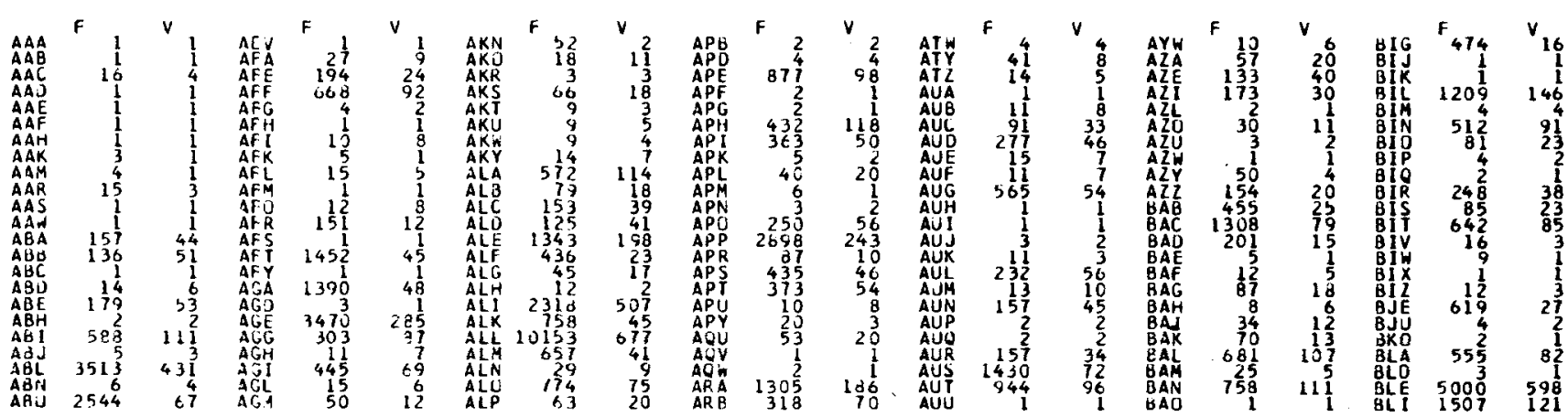


Table 2 (Continued)

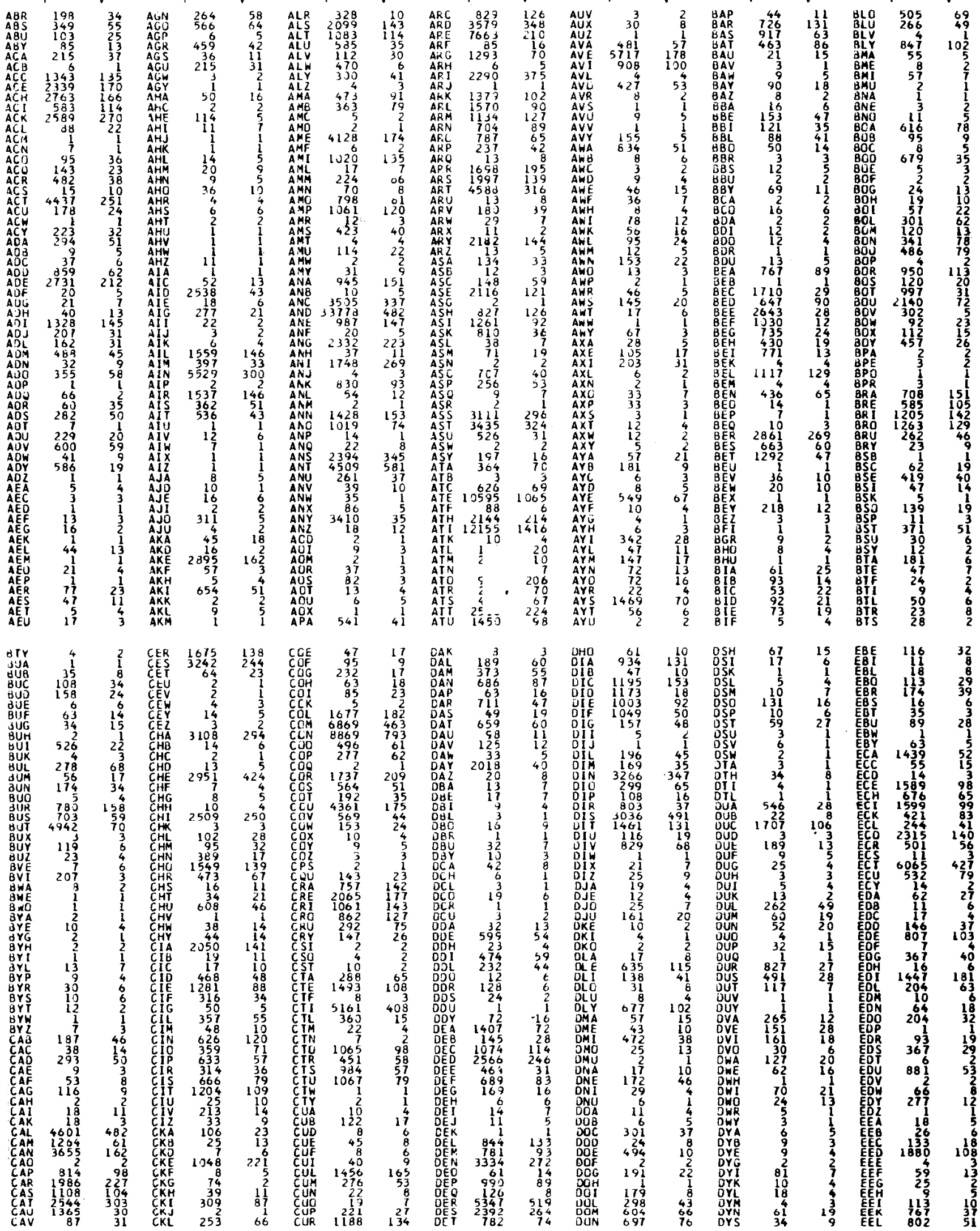


Table 2 (Continued)

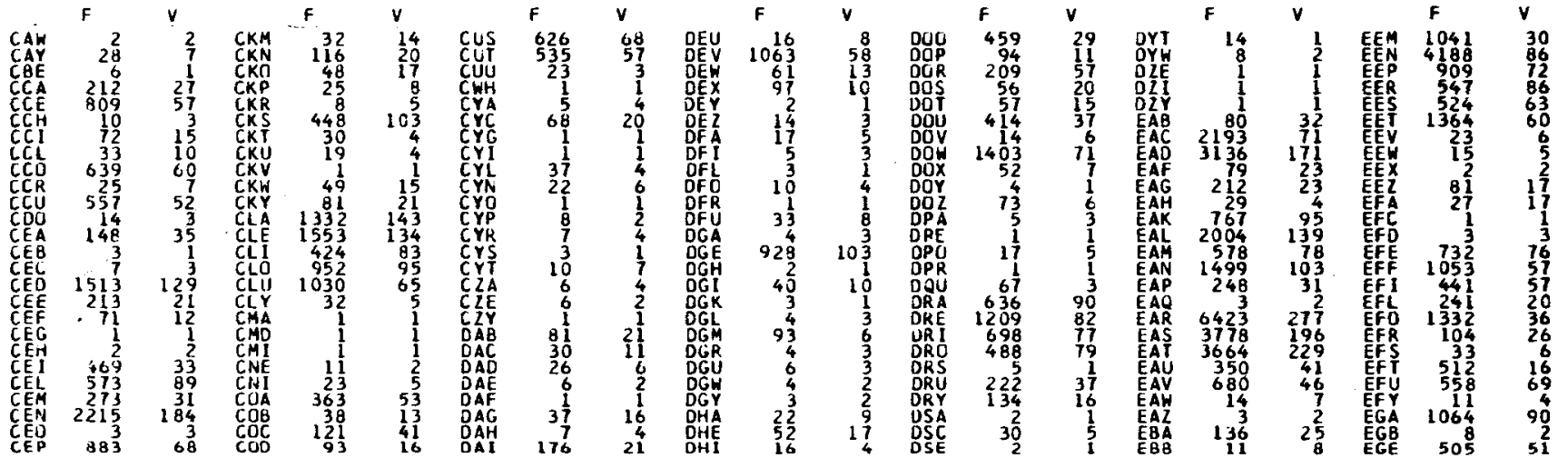

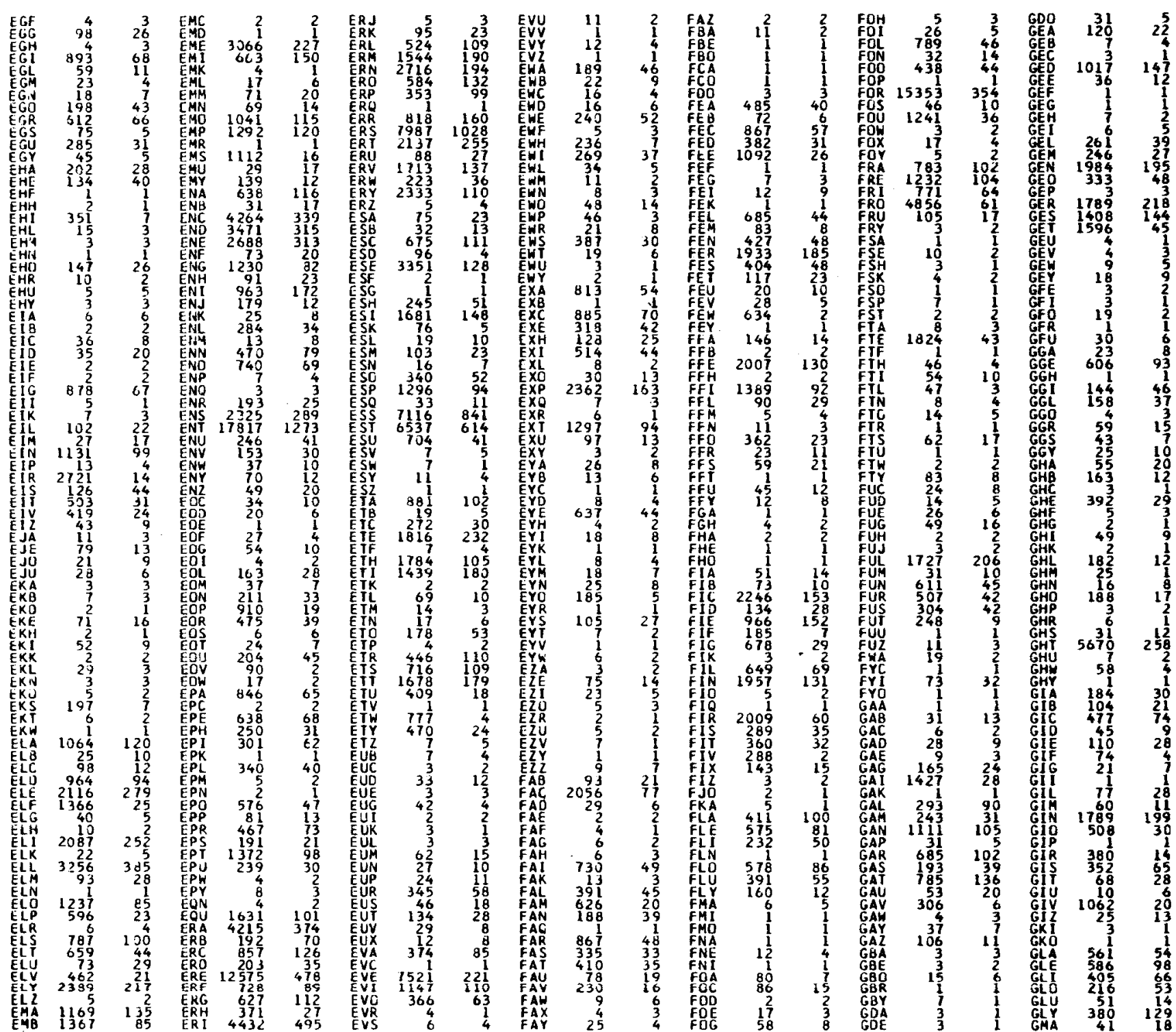


Table 2 (Continued)

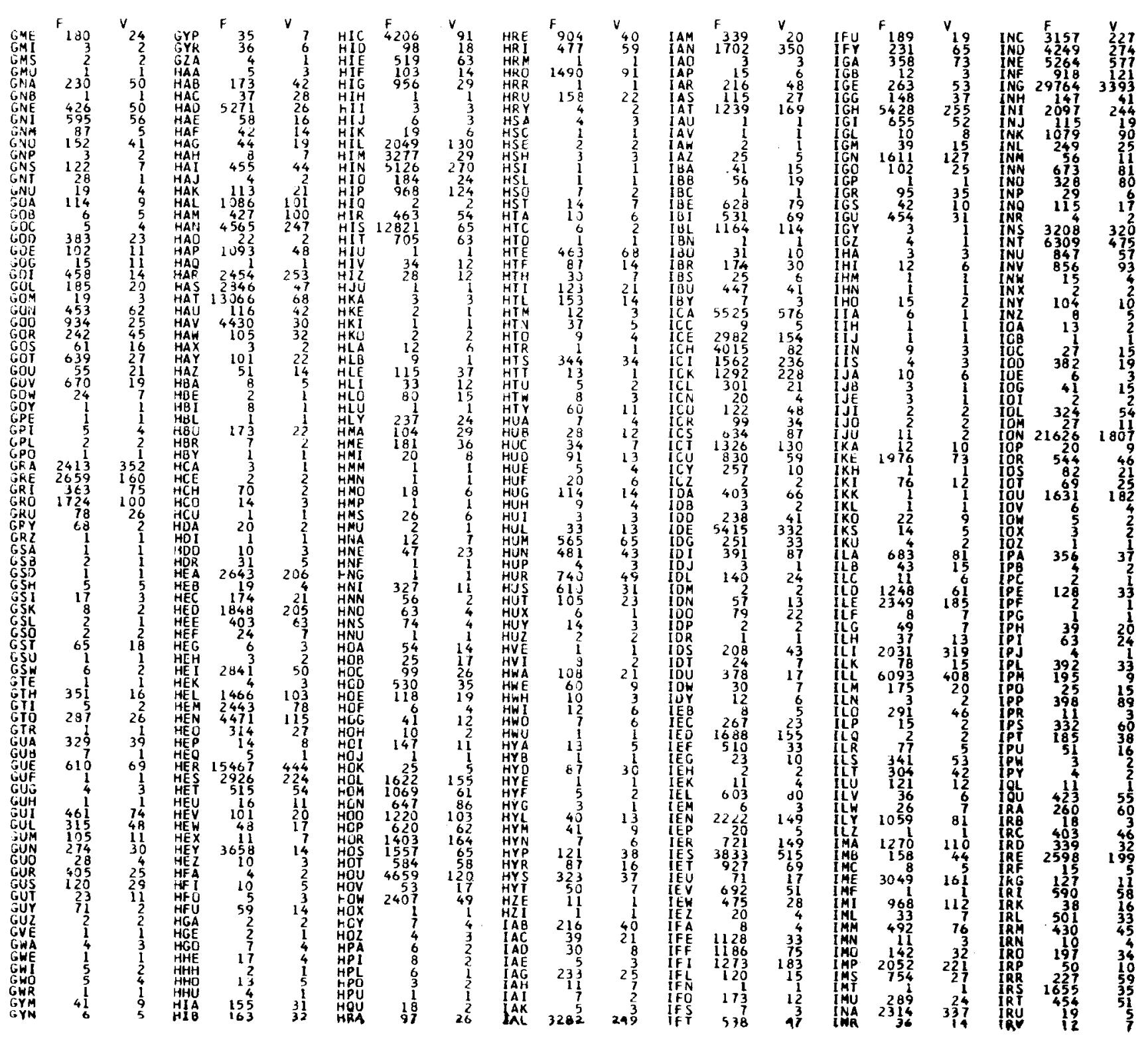

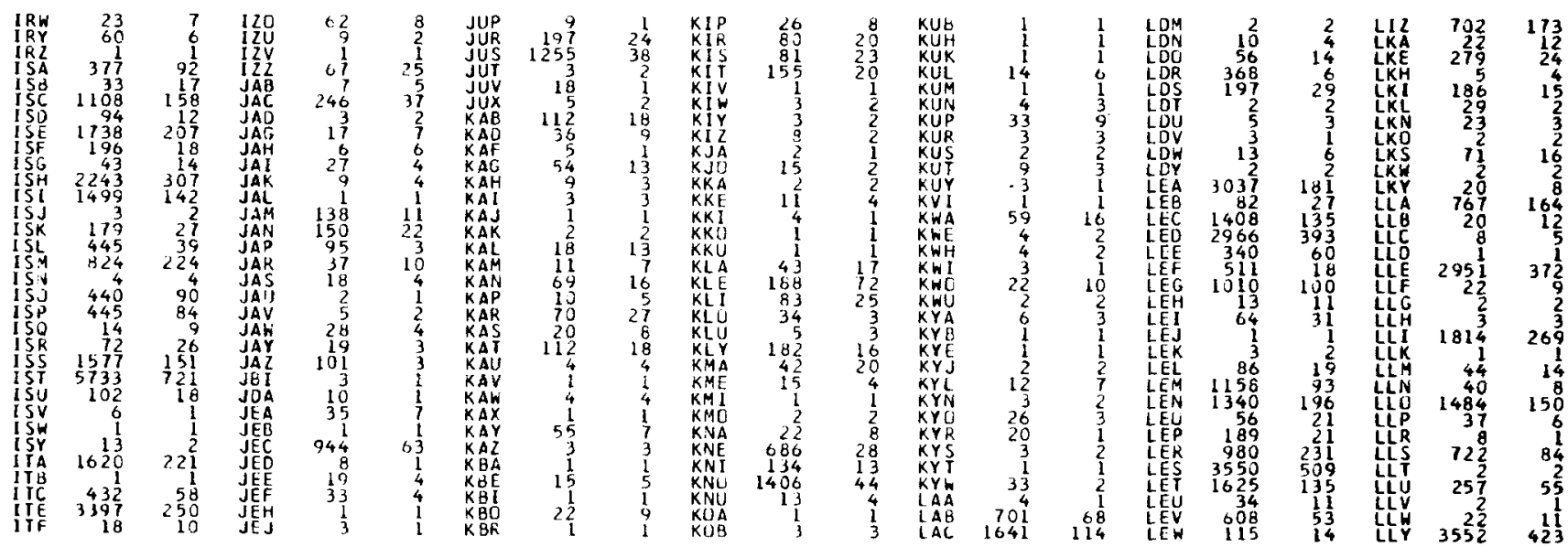


Table 2 (Continued)

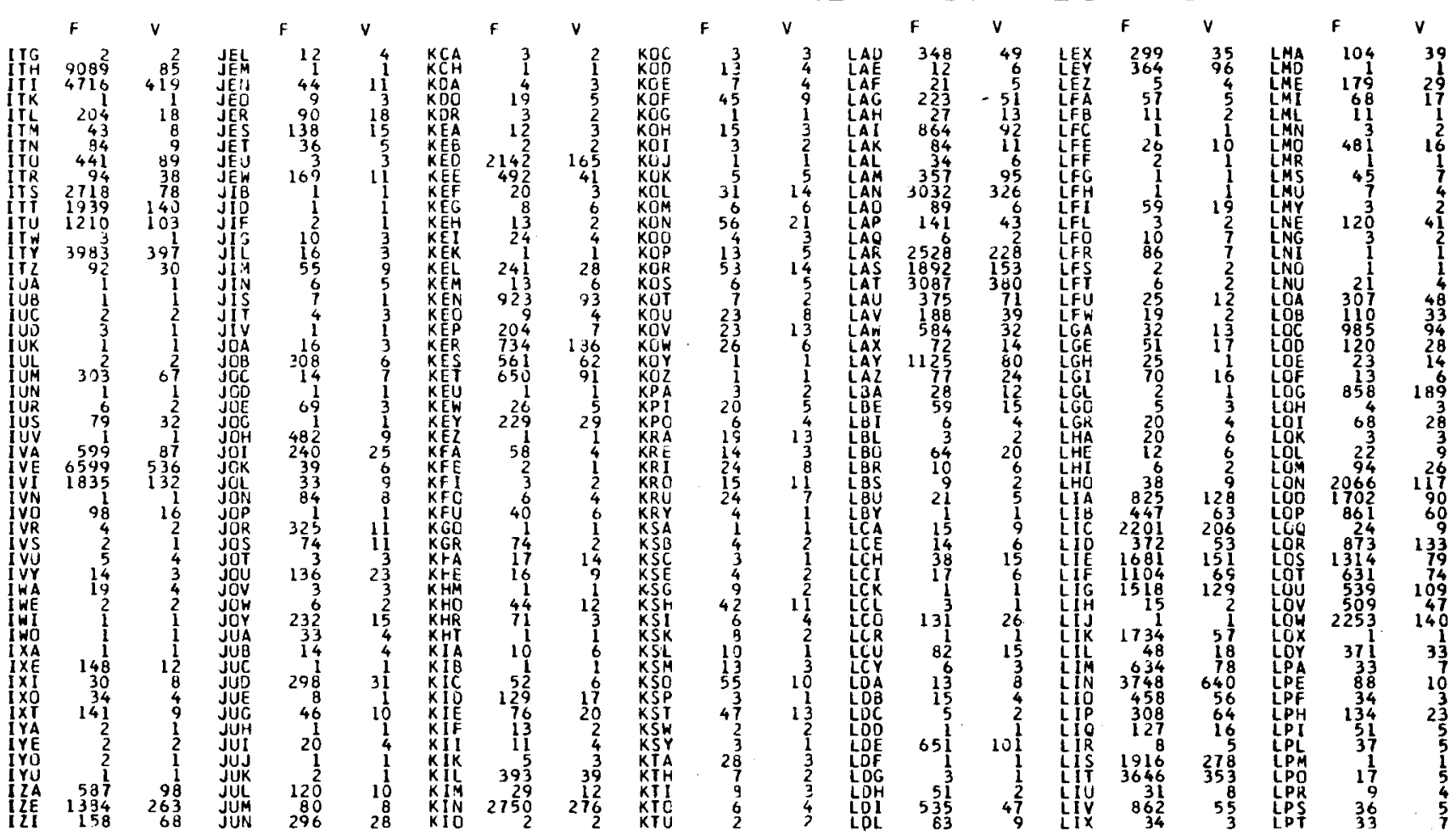

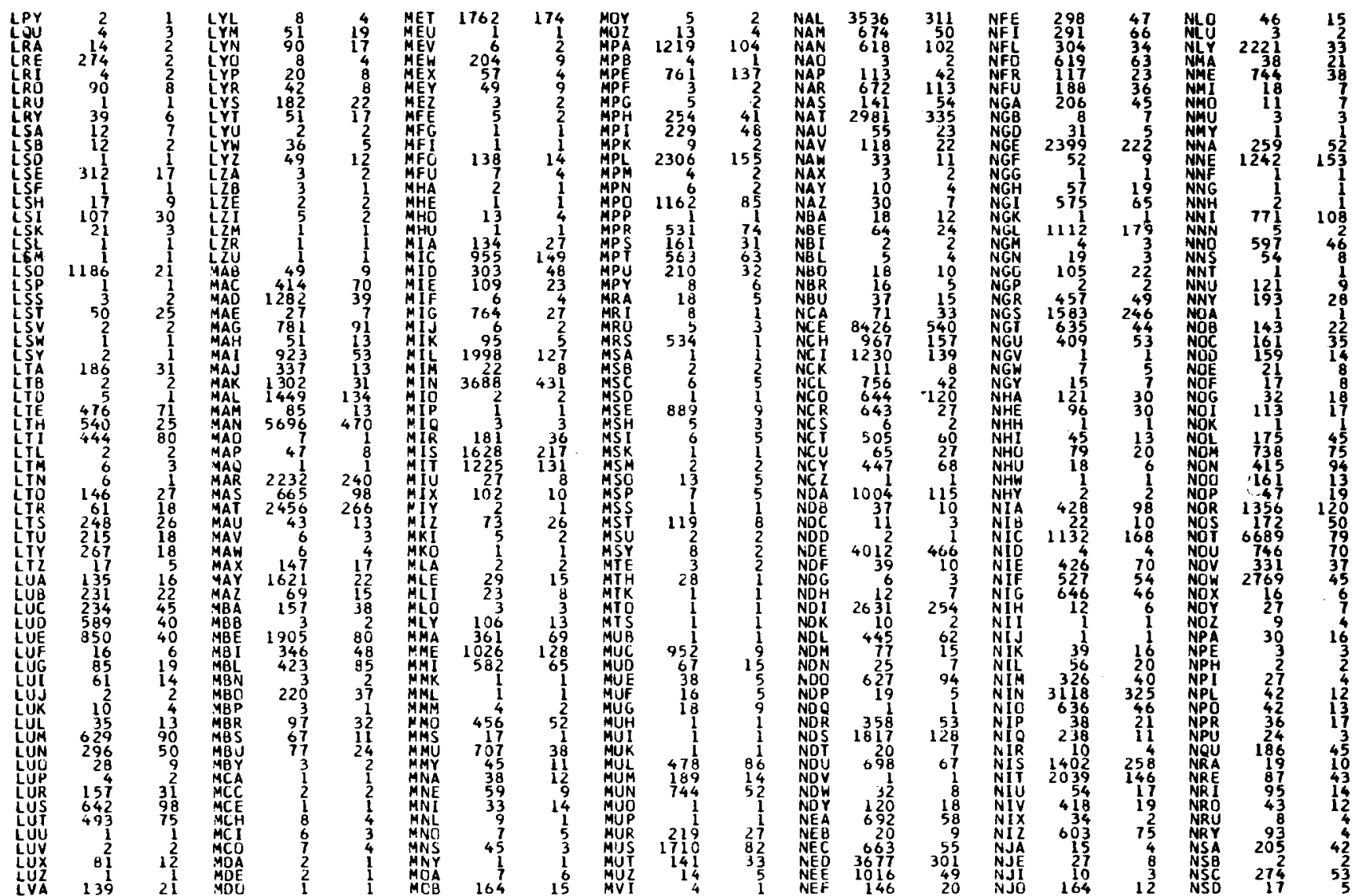


Table 2 (Continued)

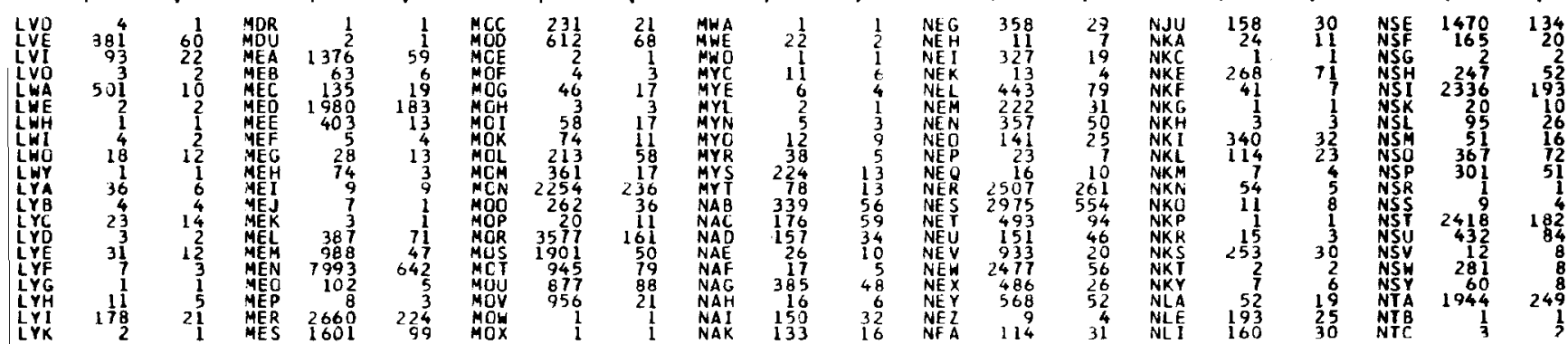

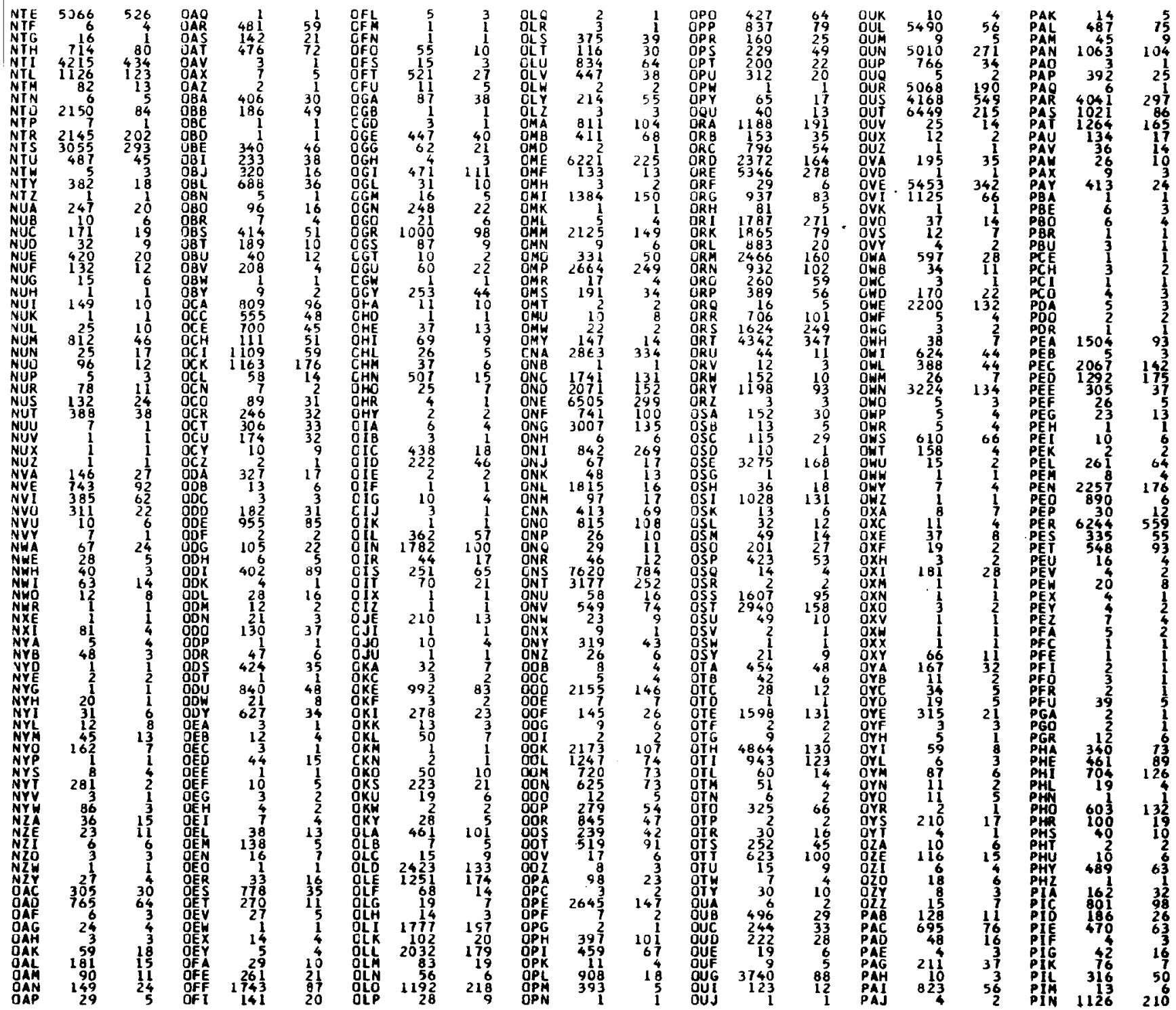

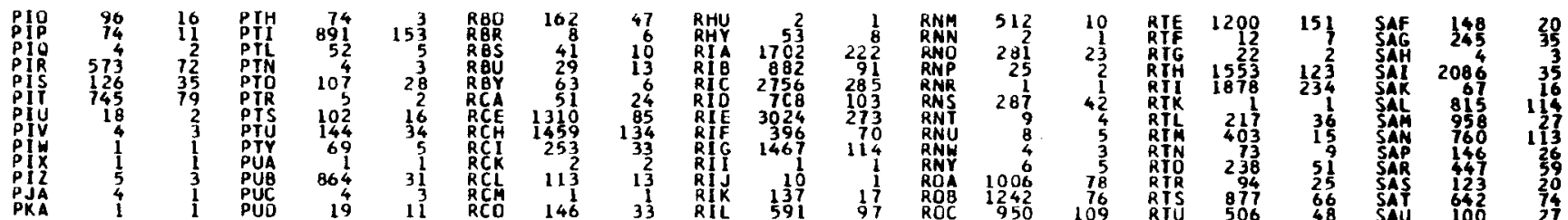


Table 2 (Continued)

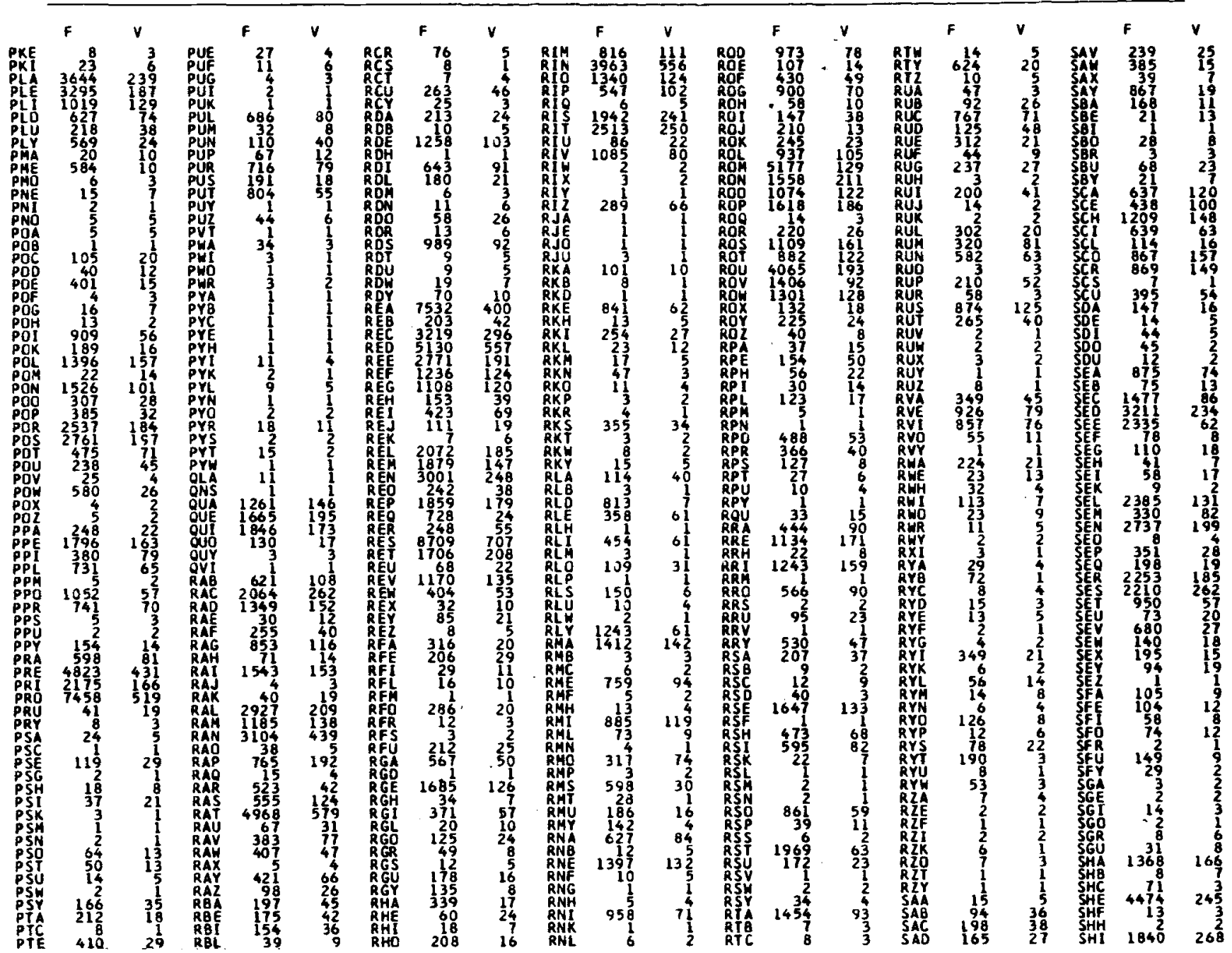

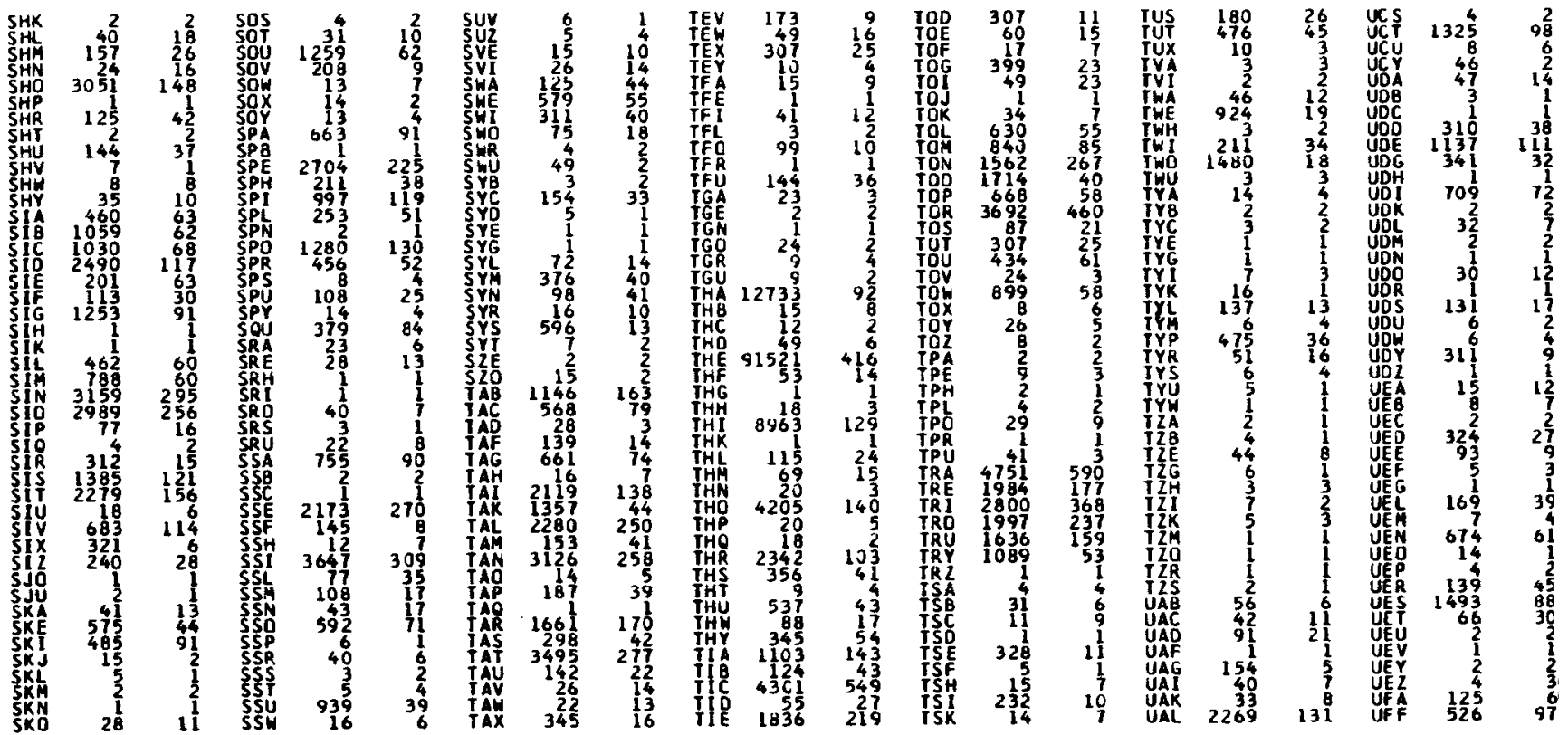


Table 2 (Continued)

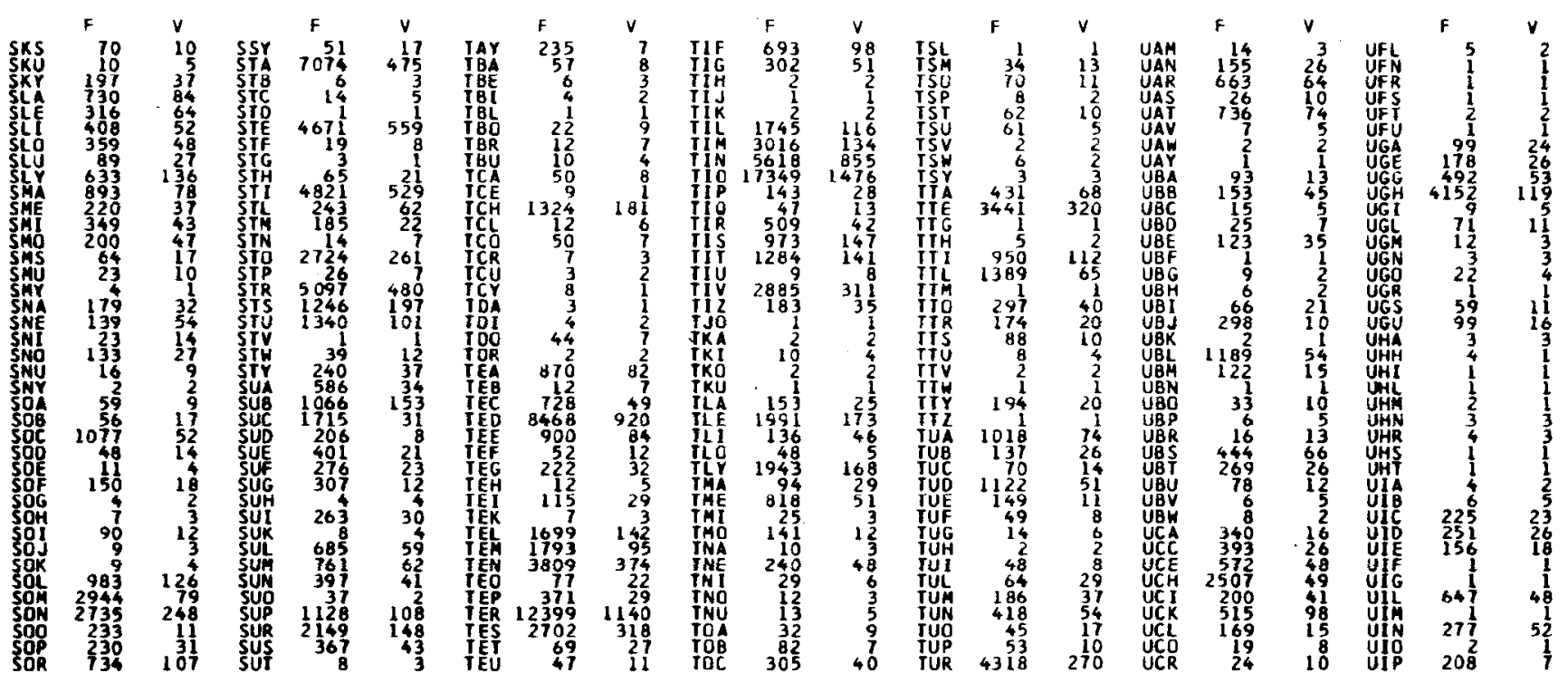

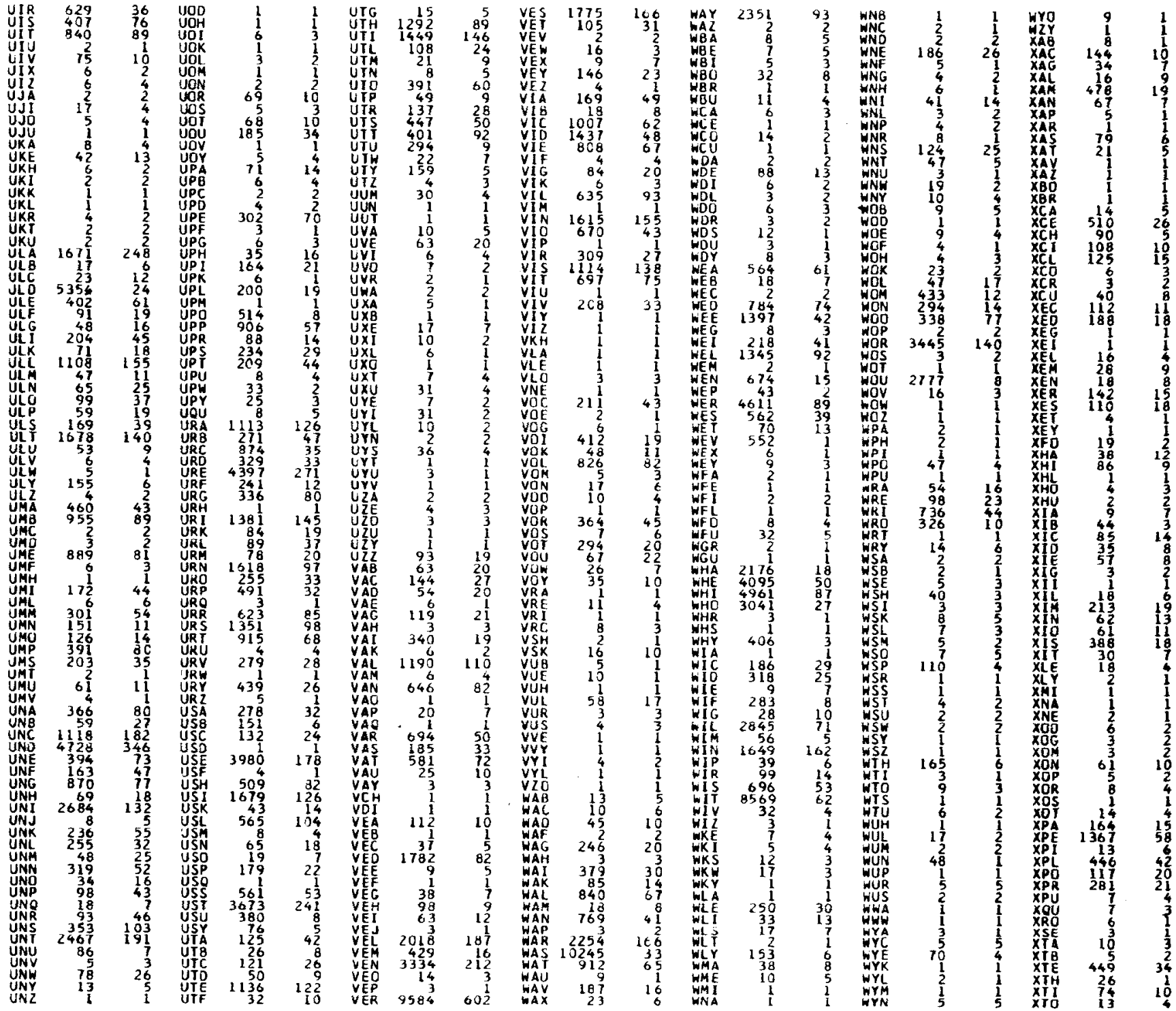


Table 2 (Continued)

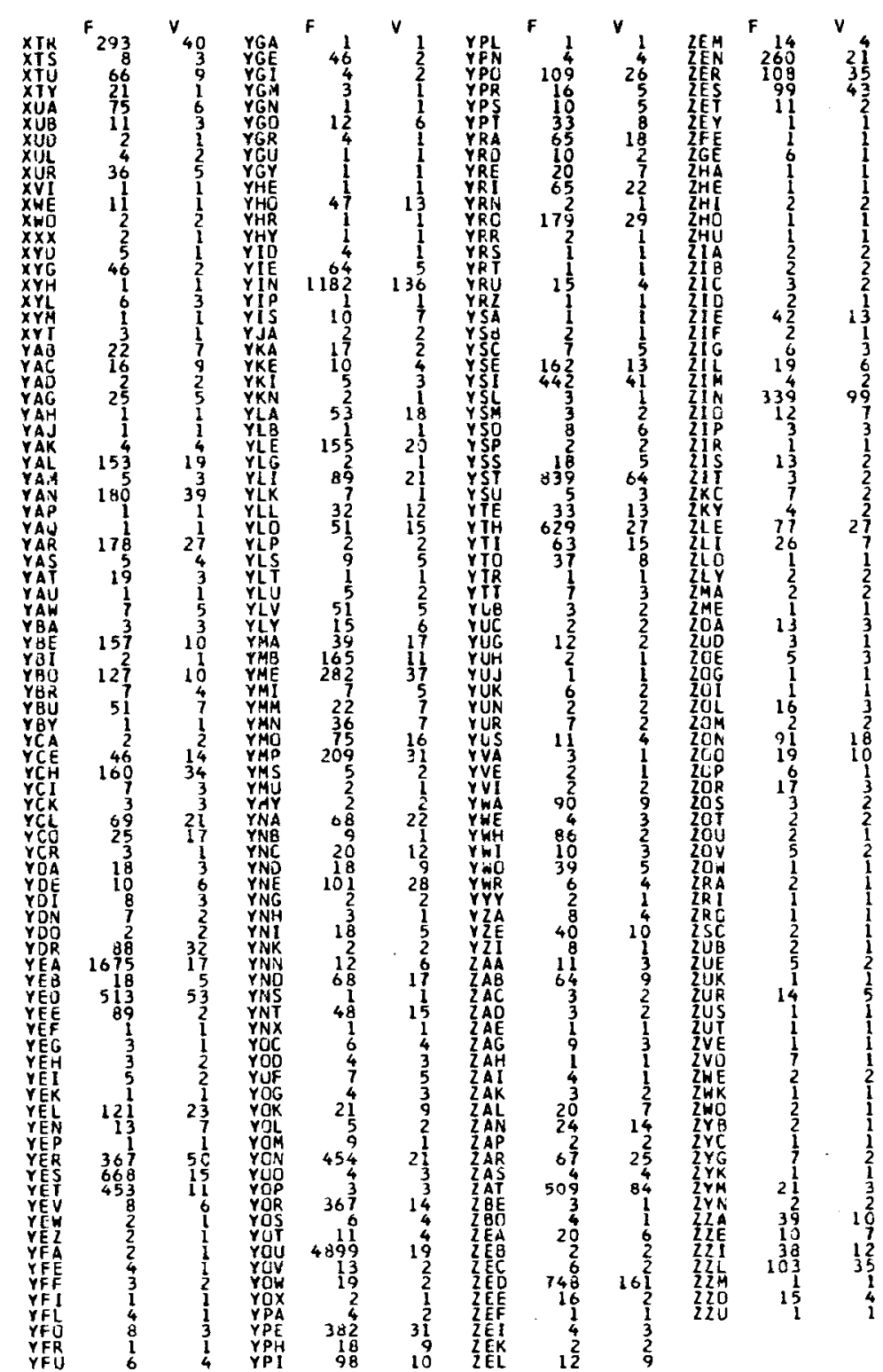

\section{REFERENCES}

KuČera, H., \& Francis, W. N. Computational analysis of present-day American English. Providence, R.I: Brown University Press, 1967.

Lysing, H. Secret writing, an introduction to cryptograms, ciphers, and codes. New York: Kemp, 1936.

Mason, M. Reading ability and letter search time: Effects of orthographic structure defined by single-letter positional frequency. Journal of Experimental Psychology: General, 1975, 1, 146-166.

Mayzner, M. S., \& Tresselt, M. E. Table of single-letter and bigram frequency counts for various word-length and letterposition combinations. Psychonomic Monograph Supplements, 1965, 1(Whole No. 2).

Solso, R. L. Positional frequency and versatility of letters for six-, seven-, and eight-letter English words. Behavior Research Methods \& Instrumentation, 1979, 11, 355-358.

Solso, R. L., \& KING, J. Frequency and versatility of letters in the English language. Behavior Research Methods \& Instrumentation, 1976, 8, 283-286.

Solso, R. L., Toppen, G. E., \& Macey, W. H. Anagram solution as a function of bigram versatility. Journal of Experimental Psychology, 1973, 100, 259-262.

TOPPER, G. E., MACEY, W. H., \& Solso, R. L. Bigram versatility and bigram frequency. Behavior Research Methods \& Instrumentation, 1973, 5, 51-53.

UNDE RWOOD, B. J., \& Schulz, R. W. Meaningfulness and verbal learning. Chicago: Lippincott, 1960.

(Received for publication May 10, 1979; revision accepted July $19,1979$. 